\title{
Katia Gavagnin, Marco Iamoni, Rocco Palermo. "The Land of Nineveh Archaeological Project: The Ceramic Repertoire from the Early Pottery Neolithic to the Sasanian Period"
}

\section{Astrid Nunn}

\section{OpenEdition}

\section{Journals}

Édition électronique

URL : http://journals.openedition.org/abstractairanica/46210

DOI : 10.4000/abstractairanica.46210

ISBN : 1961-960X

ISSN : 1961-960X

Éditeur :

CNRS (UMR 7528 Mondes iraniens et indiens), Éditions de l'IFRI

\section{Référence électronique}

Astrid Nunn, « Katia Gavagnin, Marco lamoni, Rocco Palermo. "The Land of Nineveh Archaeological Project: The Ceramic Repertoire from the Early Pottery Neolithic to the Sasanian Period" », Abstracta Iranica [En ligne], Volume 37-38-39 | 2018, document 75, mis en ligne le 30 décembre 2018, consulté le 02 octobre 2020. URL : http://journals.openedition.org/abstractairanica/46210 ; DOI : https://doi.org/ 10.4000/abstractairanica.46210

Ce document a été généré automatiquement le 2 octobre 2020.

Tous droits réservés 


\title{
Katia Gavagnin, Marco Iamoni, Rocco Palermo. "The Land of
} Nineveh Archaeological Project: The Ceramic Repertoire from the Early Pottery Neolithic to the Sasanian Period"

\author{
Astrid Nunn
}

\section{RÉFÉRENCE}

Katia Gavagnin, Marco Iamoni, Rocco Palermo. "The Land of Nineveh Archaeological Project: The Ceramic Repertoire from the Early Pottery Neolithic to the Sasanian Period", BASOR 375, 2016, p. 119-169.

1 Cet article est un résumé des résultats de la prospection qui a eu lieu dans la région de Ninive en 2012 et 2013. Le spectre chronologique est immense, puisque les tessons datent du début du VII ${ }^{\text {ème }}$ millénaire à l'époque sassanide du VII ${ }^{\text {ème }} \mathrm{s}$. ap. J.-C. Les A. sont particulièrement intéressés par le facies local, tout en plaçant la céramique dans un contexte plus large. Les grands sites assyriens ne furent pas complètement abandonnés après la fin de l'Empire assyrien. La céramique de la période "post-assyrienne/ achéménide" (p. 146-47) est un maillon qui, avec d'autres éléments du puzzle, contribuera à la reconnaissance encore difficile de cette époque. En conclusion, Le Bronze Moyen et les périodes tardives se fondent le mieux dans les connaissances actuelles. 


\section{AUTEURS}

\section{ASTRID NUNN}

Université de Munich 